\title{
ÓXIDOS DE FERRO E SUAS APLICAÇÕES EM PROCESSOS CATALÍTICOS: UMA REVISÃO
}

Luiz C. A. Oliveira*

Departamento de Química, Instituto de Ciências Exatas, Universidade Federal de Minas Gerais, CP 702, 31270-901 Belo Horizonte - MG, Brasil

José D. Fabris

Universidade Federal dos Vales do Jequitinhonha e Mucuri, 39100-000 Diamantina - MG, Brasil

Márcio C. Pereira

Instituto de Ciência, Engenharia e Tecnologia, Universidade Federal dos Vales do Jequitinhonha e Mucuri, 39803-371 Teófilo

Otoni - MG, Brasil

Recebido em 13/2/12; aceito em 23/6/12; publicado na web em 26/11/12

\begin{abstract}
IRON OXIDES AND THEIR APPLICATIONS IN CATALYTIC PROCESSES: A REVIEW. A review of most of the reported studies on the use of iron oxides as catalyst in specific processes, namely Haber-Bosch reaction, Fischer-Tropsch synthesis, Fenton oxidation and photolytic molecular splitting of water to produce gaseous hydrogen, was carried out. An essential overview is thus presented, intending to address the fundamental meaning, as well as the corresponding chemical mechanisms, and perspectives on new technological potentialities of natural and synthetic iron oxides, more specifically hematite $\left(\alpha-\mathrm{Fe}_{2} \mathrm{O}_{3}\right)$, goethite $(\alpha-\mathrm{FeOOH})$, magnetite $\left(\mathrm{Fe}_{3} \mathrm{O}_{4}\right)$ and maghemite $\left(\gamma-\mathrm{Fe}_{2} \mathrm{O}_{3}\right)$, in heterogeneous catalysis.
\end{abstract}

Keywords: iron oxides catalysts; heterogeneous catalysis; adsorption process.

\section{INTRODUÇÃOO}

Esta revisão objetiva apresentar os aspectos mais interessantes das aplicações de compostos de ferro em catálise heterogênea. $\mathrm{O}$ ferro é o elemento mais abundante da Terra, compondo $35 \%$ da massa total do planeta. ${ }^{1}$ Uma pequena parte de origem meteorítica ocorre no estado livre, mas a maior parte aparece combinada com oxigênio, silício ou enxofre. Quase todas as rochas e solos contêm ao menos traços de ferro. ${ }^{2}$ A maior parte do ferro da crosta terrestre está presente na forma de $\mathrm{Fe}^{2+}$, mas é rapidamente oxidada na superfície a $\mathrm{Fe}^{3+}$. Os principais minérios de ferro de ocorrência natural são hematita $\left(\alpha \mathrm{Fe}_{2} \mathrm{O}_{3}\right), 70 \%$ em massa de ferro, goethita $(\alpha \mathrm{FeOOH}), 63 \%$ em massa de ferro, e magnetita que também apresenta altos teores de ferro, $72 \%$ em massa. ${ }^{2}$ Esses óxidos representam uma família de materiais com notável diversidade de propriedades e uma química muito interessante devido às suas propriedades magnéticas, elétricas, físico-químicas e morfológicas, que os tornam muito importantes do ponto de vista científico e tecnológico. Dentre os diversos campos em que os óxidos de ferro são aplicados destacam-se os processos envolvendo adsorção e catálise, que têm atraído grande interesse, devido, principalmente, às suas propriedades redoxes e texturais. ${ }^{3}$

Catalisadores e adsorventes não apenas à base de óxidos de ferro têm sido usados em diversos processos industriais. ${ }^{4,5}$ Porém, os materiais de ferro são eficientes e baratos. Entre os processos mais importantes destacam-se a síntese de amônia, a conversão do monóxido a dióxido de carbono a altas temperaturas, desidrogenação do etilbenzeno a estireno, amoxidação do propeno a acrilonitrila e desidrogenação oxidativa de buteno a butadieno. ${ }^{5}$

A síntese de amônia é o processo industrial mais importante para o isolamento do nitrogênio, assim como para produção adicional de compostos nitrogenados de importância vital (ureia, ácido nítrico e fertilizantes). Este processo é quase centenário, tendo sido descoberto no início do século 20 por Fritz Haber e desenvolvido para a produção industrial por Carl Bosch. ${ }^{5}$

*e-mail: luizoliveira@qui.ufmg.br
O processo Fischer-Tropsch (FT) tem uma história de, aproximadamente, 70 anos. Atualmente, esse processo desperta grande atenção como opção para o transporte limpo de combustíveis e produção de produtos químicos. ${ }^{6}$ Nesse processo, o gás de síntese, uma mistura de $\mathrm{CO}$ e $\mathrm{H}_{2}$, obtida a partir de carvão, turfa, biomassa ou gás natural é convertido em uma mistura de hidrocarbonetos. Combustíveis produzidos com o processo de FT são de alta qualidade, devido a uma baixa aromaticidade e à ausência de enxofre. Outros produtos valiosos, além de combustíveis, podem ser obtidos com o FT, em combinação com outros processos, por exemplo, eteno, propeno, -olefinas, cetonas, solventes, alcoóis e ceras. ${ }^{7} \mathrm{O}$ processo ainda esbarra no alto valor envolvido no processo e, por isso, apenas países com dificuldade de aquisição do combustível de origem fóssil empregam o processo. Catalisadores à base de cobalto são muito ativos, embora o ferro possa ser mais apropriado para gases de síntese com baixo teor de hidrogênio, tais como os derivados de carvão, devido à sua promoção da reação de deslocamento de gás d'água. ${ }^{8}$

Um dos temas mais debatidos atualmente é, sem dúvida, a questão ambiental, especialmente no que se refere à degradação efetiva dos diversos poluentes orgânicos presentes em águas residuárias. ${ }^{9}$ A reação Fenton $\left(\mathrm{Fe}^{2+}+\mathrm{H}_{2} \mathrm{O}_{2} \rightarrow \mathrm{Fe}^{3+}+{ }^{-} \mathrm{OH}+{ }^{\circ} \mathrm{OH}\right)$, envolvendo peróxido de hidrogênio e $\mathrm{Fe}^{2+}$ em solução, é usada para degradar diversos contaminantes, como efluentes contendo corantes têxteis. ${ }^{10-13}$ A substituição do sal solúvel de $\mathrm{Fe}^{2+}$ por sistemas catalíticos heterogêneos à base de compostos sólidos de ferro tem sido estudada, a fim de diminuir as desvantagens do processo. Sistemas redoxes heterogêneos ativos estão substituindo cada vez mais os sistemas redoxes homogêneos na pesquisa em catálise, ${ }^{14,15} \mathrm{em}$ algumas aplicações tecnológicas e na remediação de contaminações ambientais. Além disso, os diferentes óxidos de ferro têm sido aplicados como adsorventes de diferentes moléculas e íons metálicos, principalmente em processos de remediação ambiental. Uma pesquisa realizada no banco de dados do ISI Web of Knowledge empregando as palavras-chave iron oxide and catalysis e ainda iron oxides and adsorption indicou que foram publicados cerca de 760 artigos em periódicos internacionais no período de 
2009-2011, o que mostra o grande interesse por pesquisas envolvendo óxidos de ferro em processos de adsorção e catálise.

\section{CATÁLISE E OS ÓXIDOS DE FERRO}

\section{Processo Haber-Bosch}

No século XX ocorreu uma das maiores descobertas no mundo da catálise, sendo 2/06/1909 um marco histórico, quando o químico alemão K. Fritz Haber descobriu uma forma eficiente de preparar grandes quantidades de amoníaco a partir do hidrogênio e azoto moleculares. Dois anos após o artigo inicial, em 1910, a empresa Basf comprou sua patente. Carl Bosch, engenheiro metalúrgico da empresa, transformou a possibilidade teórica prevista por Haber em uma realidade prática. Os aperfeiçoamentos renderiam a Bosch o Prêmio Nobel de Química em 1931. ${ }^{16}$

A reação entre os gases $\mathrm{N}_{2}$ e $\mathrm{H}_{2}\left(\mathrm{~N}_{2(\mathrm{~g})}+3 \mathrm{H}_{2(\mathrm{~g})} \leftrightarrows 2 \mathrm{NH}_{3(\mathrm{~g})}\right)$ responsável pelo processo Haber-Bosch é exotérmica $(\Delta \mathrm{H}=-92,22$ $\mathrm{kJ} \mathrm{mol}^{-1}$ ) e é realizada sob altas pressões e temperaturas. Na presença de catalisadores à base de ferro, a reação de produção de amônia ocorre com grande rendimento. O catalisador de ferro mais utilizado é a magnetita $\left(\mathrm{Fe}_{3} \mathrm{O}_{4}\right)$ enriquecida, frequentemente, com óxidos de $\mathrm{Al}$ e $\mathrm{K}$ (ou $\mathrm{Ca}, \mathrm{Mg}, \mathrm{Si}$ ), sendo que o ótimo desempenho do catalisador exige temperaturas de reação em torno de $400{ }^{\circ} \mathrm{C}$ e pressões de 150 $300 \mathrm{~atm}$. Como metal de transição, o ferro possui ocupação parcial dos orbitais d, representando uma superfície adequada para a adsorção e dissociação de moléculas de $\mathrm{N}_{2}{ }^{5}$

O processo Haber foi adotado inicialmente para as necessidades militares. Atualmente, metade do total do nitrogênio produzido no mundo é usada para a produção de fertilizantes utilizados na agricultura. A outra metade é usada para a fabricação de xampus, detergentes com amoníaco, náilon, pigmentos usados nas fotografias em cores, hidrazina (combustível para foguetes), ácido nítrico, trinitrotolueno e outros explosivos, medicamentos vasodilatadores cardíacos, anestésicos, antibióticos, germicidas, entre outros.

\section{Processo Fischer-Tropsch}

A descoberta da "síntese da gasolina" por Fischer e Tropsch (FT), publicada em 1926, relatava a utilização de ferro e cobalto como catalisadores e, até hoje, ambos continuam sendo os metais utilizados para aplicação industrial do processo. ${ }^{6}$

$\mathrm{O}$ processo FT é catalisado por óxidos de ferro e cobalto a pressões de 1-60 bar e temperaturas de $200-300{ }^{\circ} \mathrm{C}$. A síntese de FT é uma reação de polimerização na superfície do catalisador. Os reagentes, $\mathrm{CO}$ e $\mathrm{H}_{2}$, adsorvem-se, dissociam-se e reagem na superfície do catalisador para formar iniciadores de cadeia $\left({ }^{\circ} \mathrm{CH}_{3}\right)$, monômeros de metileno $\left(-\mathrm{CH}_{2}-\right)$ e água. Os hidrocarbonetos são formados pela inserção $\mathrm{CH}_{2}$ em ligações metal-alquil e subsequente desidrogenação ou hidrogenação, de uma $\alpha$-olefina ou parafina, respectivamente. ${ }^{7}$

Os catalisadores à base de ferro necessitam de promotores alcalinos para atingir elevada atividade e estabilidade (por exemplo, $0,5 \%$ em massa de $\mathrm{K}_{2} \mathrm{O}$ ). A adição de $\mathrm{Cu}$ pode facilitar a redução química do óxido de ferro; o $\mathrm{SiO}_{2}$ e o $\mathrm{Al}_{2} \mathrm{O}_{3}$ podem agir como promotores estruturais. Além disso, o manganês pode fornecer algum controle de seletividade, devido ao aumento da oleofilicidade do catalisador. ${ }^{6}$

Esses catalisadores têm uma série de vantagens sobre os catalisadores de cobalto. Eles são menos onerosos e prontamente disponíveis; além disso, permitem que o processo de síntese seja intensificado de 10 a 20 vezes, pois são ativos e estáveis ao longo de uma ampla faixa de temperatura e pressão, com diferentes razões $\mathrm{H}_{2}$ : $\mathrm{CO}$ (gás de síntese) no gás de partida. ${ }^{17}$

Outra questão a ser considerada é com relação à mistura de gás, uma vez que a purificação dos gases, dependendo da sua origem, pode aumentar o custo do processo. O gás de síntese, necessário para o processo FT pode ser obtido por reforma a vapor ou por oxidação parcial de combustíveis fósseis como carvão, gás natural, resíduos de refinaria, biomassa ou efluentes gasosos.

Normalmente, a combinação de processos de produção na síntese de gás é realizada com uma relação estequiométrica de hidrogênio e monóxido de carbono. ${ }^{7} \mathrm{Na}$ conversão do monóxido a dióxido de carbono, os óxidos de ferro catalisam a reação na faixa de 350 a $400{ }^{\circ} \mathrm{C}$, sob condições cinéticas favoráveis. Os óxidos de ferro usados nesse estágio são comercializados, em sua maioria, na forma de hematita $\left(\alpha-\mathrm{Fe}_{2} \mathrm{O}_{3}\right)$, mas em alguns casos podem ser encontrados como maghemita $\left(\gamma-\mathrm{Fe}_{2} \mathrm{O}_{3}\right)$ ou goethita $(\alpha-\mathrm{FeOOH})$. Esses materiais devem ser reduzidos quimicamente, para formar a espécie ativa, i.e., magnetita $\left(\mathrm{Fe}_{3} \mathrm{O}_{4}\right)$. A natureza do estado precursor influencia o grau de sinterização do sólido durante o processo de redução.

As propriedades e o desempenho dos catalisadores industriais, assim como os processos de redução química, são alterados pela adição de promotores. Encontram-se na literatura estudos envolvendo catalisadores dopados com $\mathrm{Cu}^{2+}, \mathrm{Ni}^{2+}, \mathrm{Mg}^{2+}, \mathrm{Co}^{2+}, \mathrm{Al}^{3+}, \mathrm{Mn}^{2+}, \mathrm{Li}^{+}, \mathrm{Na}^{+}$, $\mathrm{K}^{+}, \mathrm{Ba}^{2+} \mathrm{e} \mathrm{Si}^{4+}{ }^{18}$ Entre eles, o cobre foi considerado o mais promissor, pois aumenta significativamente a atividade catalítica da magnetita. ${ }^{19}$ As principais reações envolvidas no processo são:

$$
\begin{array}{ll}
\mathrm{nCO}+(2 \mathrm{n}+1) \mathrm{H}_{2} \rightarrow \mathrm{C}_{\mathrm{n}} \mathrm{H}_{2 \mathrm{n}+2}+\mathrm{nH}_{2} \mathrm{O} & \text { Produção de parafina } \\
\mathrm{nCO}+(2 \mathrm{n}) \mathrm{H}_{2} \rightarrow \mathrm{C}_{\mathrm{n}} \mathrm{H}_{2 \mathrm{n}}+\mathrm{nH}_{2} \mathrm{O} & \text { Produção de olefina }
\end{array}
$$

A reação efetuada acima de $400{ }^{\circ} \mathrm{C}$ produz reações secundárias indesejadas, como a formação de metano. ${ }^{20}$

\section{Processo Fenton}

O sistema Fenton foi descoberto em 1894 e ainda hoje se apresenta como um dos métodos mais promissores para tratamento de efluentes. O processo Fenton tradicional envolve a decomposição de peróxido de hidrogênio a formas intermediárias de radicais livres (Equação 1), os quais possuem potencial de redução maior que o próprio peróxido.

$$
\mathrm{Fe}^{2+}+\mathrm{H}_{2} \mathrm{O}_{2} \rightarrow \mathrm{Fe}^{3+}+\cdot{ }^{\cdot} \mathrm{OH}+{ }^{-} \mathrm{OH}
$$

O processo Fenton clássico utiliza um sal solúvel de $\mathrm{Fe}^{2+}$. Embora seja altamente eficiente, esse sistema apresenta alguns inconvenientes, tais como, necessidade de $\mathrm{pH}$ abaixo de 3 para que os íons Fe estejam na forma solúvel; formação de resíduo (precipitado de hidróxido de ferro (III) chamado de lodo) devido à etapa de neutralização, que também deverá ser descartado no final do processo e, dificuldade de recuperação do catalisador para reutilização.

O desenvolvimento dos sistemas heterogêneos, como uma alternativa ao processo tradicional, tem recebido considerável interesse da área acadêmica, visto que o precursor é uma forma de ferro diferente de um sal de ferro solúvel, i.e., são sistemas de ferro imobilizados em uma matriz sólida (geralmente óxidos de ferro). ${ }^{21-28}$ Nos sistemas heterogêneos, a etapa de controle do $\mathrm{pH}$ para próximo de 3 e posterior neutralização podem ser evitadas. Existe, porém, desvantagens cinéticas já que a maioria dos óxidos de ferro apresenta o ferro no estado de oxidação 3+. Uma vez que o Fe no estado de oxidação 2+é o que catalisa com maior eficiência a decomposição do $\mathrm{H}_{2} \mathrm{O}_{2}$, pode-se promover, de maneira controlada, a transformação de $\mathrm{Fe}^{3+}$ a Fe ${ }^{2+}$ pelo tratamento térmico em presença de $\mathrm{H}_{2}$. Nesse caso, a reação ocorre sem que o ferro passe para a solução, i.e., a reação se dá via processo heterogêneo, o que facilita grandemente a reação já que o $\mathrm{pH}$ de operação pode ser próximo de 7. Dessa forma, as etapas de ajuste do 
pH para próximo de 3 e posterior neutralização podem ser evitadas.

Diversos óxidos de ferro como magnetita (fórmula ideal, $\mathrm{Fe}_{3} \mathrm{O}_{4}$ ), hematita $\left(\alpha-\mathrm{Fe}_{2} \mathrm{O}_{3}\right)$, goethita $(\alpha-\mathrm{FeOOH})$ ou ferridrita $\left(\mathrm{Fe}_{5} \mathrm{HO}_{8}\right.$. $4 \mathrm{H}_{2} \mathrm{O}$ ), têm sido usados em substituição ao sistema com o $\mathrm{Fe}^{2+}$ solúvel. ${ }^{29,30} \mathrm{~A}$ utilização destes óxidos objetiva a possibilidade do emprego de um material de baixo custo, que opere em $\mathrm{pH}$ próximo da neutralidade, que possa ser reciclado e que diminua a geração de lodo. ${ }^{31}$

Novos sistemas envolvendo a dopagem dos óxidos de ferro com diferentes metais de transição têm sido empregados visando facilitar as transferências eletrônicas e, consequentemente, maximizar a atividade catalítica do processo heterogêneo. Nosso grupo de pesquisa desenvolveu recentemente catalisadores com elevada eficiência na decomposição de $\mathrm{H}_{2} \mathrm{O}_{2}$ contendo $\mathrm{Cu}, \mathrm{Nb}, \mathrm{Mn}$, Co e $\mathrm{Cr}$ incorporados aos óxidos de ferro. ${ }^{24-26,32-36}$ Além disso, o mecanismo Fenton tem sido fundamentado com o auxílio de técnicas analíticas mais sensíveis, tal como análise por espectrometria de massas com ionização via electrospray (ESI-MS). Essa técnica permite identificar intermediários de oxidação, produtos formados antes da mineralização, inclusive mostrando as sucessivas hidroxilações da estrutura orgânica durante o processo do tipo-Fenton. ${ }^{24}$ A Figura 1a apresenta um estudo via ESI-MS dos produtos de degradação da quinolina. O sinal $\mathrm{m} / \mathrm{z}=$ 130 é referente à molécula de quinolina antes da sua oxidação pela reação do tipo Fenton. Devido à reação do tipo Fenton, aparecem sinais, por exemplo, com $\mathrm{m} / \mathrm{z}=146$ e 178 que se referem à entrada de hidroxilas na estrutura da quinolina, sugerindo a formação de radicais - OH promovida pela reação de decomposição de $\mathrm{H}_{2} \mathrm{O}_{2}$ catalisada pelo óxido de ferro. ${ }^{37}$ As possíveis estruturas devem estar relacionadas, como descrito anteriormente, à oxidação da molécula de quinolina promovida por radicais ${ }^{\bullet} \mathrm{OH}$.

Outros pesquisadores têm usado óxidos de ferro depositados em
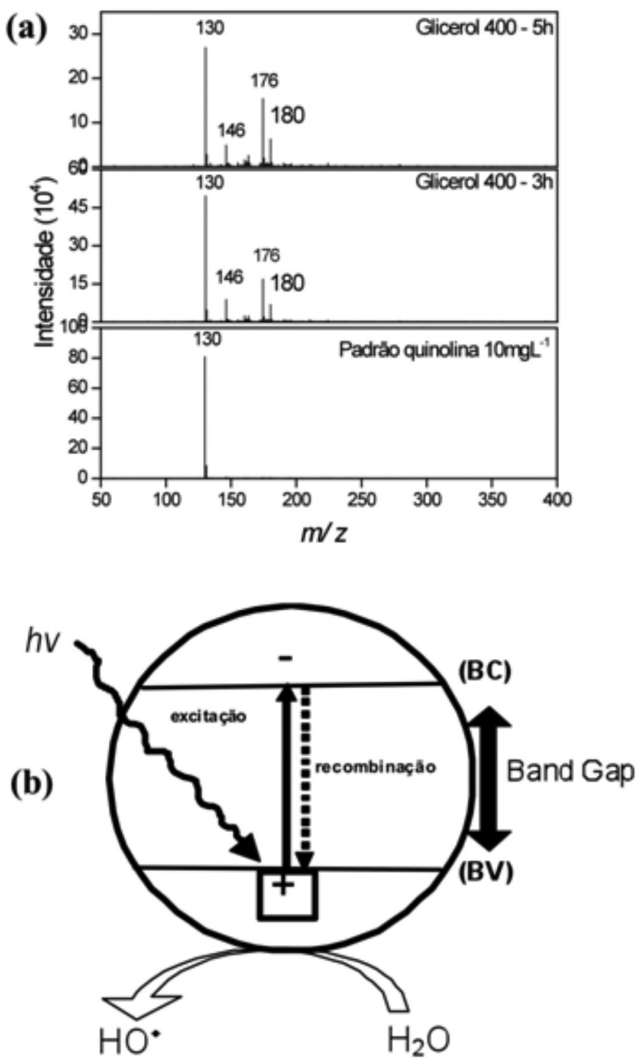

Figura 1. (a) Espectros de massas dos produtos de oxidação da quinolina empregando o processo Fenton após redução química dos materiais na presença de glicerina. (b) Esquema representativo de um semicondutor mostrando a banda de valência $(B V)$ e a banda de condução $(B C)$ matrizes com elevada área específica, funcionando como suportes, com a intenção de aumentar a dispersão das espécies de ferro e, consequentemente, sua atividade catalítica. Diferentes suportes, tais como, zeólita, MCM, argila, nióbia e carvão ativado têm sido empregados e apresentado resultados extremamente promissores. ${ }^{38-42}$

\section{Fotocatálise}

Entre as tecnologias em desenvolvimento para tratamento de efluentes e as tecnologias desejáveis, baseadas na sustentabilidade ambiental, existe um grande abismo científico e tecnológico. Dentre as técnicas de tratamento disponíveis, a fotocatálise é considerada bastante promissora, já que faz uso de materiais baratos e com elevada eficiência.

O princípio da fotocatálise envolve a ativação de um semicondutor por luz solar ou artificial. Um semicondutor é caracterizado por bandas de valência (BV) e bandas de condução (BC) sendo a região entre elas chamada de band gap. Uma representação esquemática de um semicondutor é mostrada na Figura $1 \mathrm{~b}$.

A absorção de fótons com energia igual ou superior à energia de band gap resulta na promoção de um elétron da banda de valência para a banda de condução, com geração concomitante de uma lacuna na banda de valência. As lacunas apresentam potencial de redução suficientemente grande para oxidar as moléculas de água adsorvidas na superfície do catalisador e formar radicais ${ }^{\bullet} \mathrm{OH}$, que são altamente oxidantes e não seletivos. ${ }^{43}$

Um dos aspectos interessantes da fotocatálise é a possibilidade de utilização da luz solar para ativação do semicondutor. Para otimizar o processo fotocatalítico com aproveitamento da radiação solar, um dos aspectos que devem ser aprofundados nas pesquisas é a ampliação do espectro de absorção de luz pelo catalisador na região do visível.

Geralmente os fotocatalisadores utilizados são óxidos de metais de transição, tais como, $\mathrm{Fe}_{2} \mathrm{O}_{3}, \mathrm{ZnO}, \mathrm{ZnS}, \mathrm{CdS}$ e $\mathrm{TiO}_{2}{ }^{44}$ Idealmente, um semicondutor empregado como catalisador no processo de fotocatálise, com a finalidade de degradar compostos orgânicos, deve ser quimicamente inerte, fotocataliticamente estável na condição aplicada, facilmente sintetizado e fácil de usar. Entre esses semicondutores, o dióxido de titânio é o mais utilizado devido suas propriedades, tais como, elevada estabilidade química, alta fotossensibilidade, natureza não tóxica, entre outras. ${ }^{45}$ Mais recentemente, óxidos de ferro como hematita e goethita têm recebido atenção especial, devido ao menor valor de band gap, o que possibilita o emprego de luz solar no processo fotocatalítico. De fato, esses óxidos geralmente possuem valores de band gap relativamente baixos, cerca de $2,2 \mathrm{eV}^{46}$ Este valor é menor do que o band gap do $\mathrm{TiO}_{2}(3,2 \mathrm{eV}),{ }^{47}$ portanto, estes materiais podem absorver energias em comprimentos de onda menores (próximo à luz visível) do que o $\mathrm{TiO}_{2}$ (absorve em $\lambda<387$ $\mathrm{nm})$, para formar pares $\mathrm{e}^{-} / \mathrm{h}^{+}$.

\section{Química fina e outras reações com apelo tecnológico}

Óxidos de ferro, mais especificamente, magnetita dopada com Co e Mn tem sido usada como catalisador heterogêneo em química fina, para oxidação aeróbica de vários alquenos monoterpênicos para obtenção de novos produtos com valor agregado, como derivados mono-oxigenados alílicos e epóxidos. ${ }^{48} \mathrm{O}$ uso de óxidos de ferro nesses processos catalíticos de oxidação aeróbica oferece grandes vantagens práticas uma vez que o catalisador é relativamente barato, fácil de sintetizar, tem alta seletividade, a reação catalítica pode ser realizada em condições que não necessitam de solvente, o catalisador pode ser recuperado e reusado em vários ciclos catalíticos sem perda considerável de atividade. Além disso, após a desativação do catalisador devido à formação de espécies oxidadas na superfície, 
um simples tratamento térmico a $250{ }^{\circ} \mathrm{C}$ sob fluxo de $\mathrm{H}_{2}$ é capaz de reduzir quimicamente as espécies de óxidos de ferro (III) na superfície para formar novamente a espécie cataliticamente ativa, i.e., magnetita.

Catalisadores naturais à base de óxidos de ferro modificados têm sido desenvolvidos para a oxidação de tióis em condições fracamente alcalinas.$^{49} \mathrm{O}$ acoplamento oxidativo de tióis (mercaptanos) em dissulfetos é uma importante reação em química e na indústria de petróleo. Os dissulfetos são usados como intermediários chave em várias reações de síntese orgânica. Na indústria, os dissulfetos são geralmente usados na vulcanização de borrachas e elastômeros. A oxidação de tióis em dissulfetos, mais conhecido como processo Merox, é o procedimento mais usado na indústria de refino do petróleo para remoção de tióis que causam sérios problemas ambientais. ${ }^{50} \mathrm{~A}$ maior parte dos métodos descritos na literatura para oxidação de tióis usa oxidantes estequiométricos como dicromato, permanganato e peróxidos metálicos que geram grandes quantidades de resíduo no final do processo, além de serem frequentemente tóxicos. ${ }^{51-53}$ Assim, a oxidação catalítica na presença de óxidos de ferro tem grandes vantagens em relação aos processos homogêneos usados para esse propósito, como não precisar de cocatalisador, ter alta seletividade, não gerar resíduos e, o catalisador pode ser reciclado, regenerado e reusado.

Outra reação tecnologicamente importante é a clivagem fotocatalítica da água para produzir hidrogênio. Atualmente, cerca de $95 \%$ da produção mundial de hidrogênio é derivada de combustíveis fósseis. ${ }^{54}$ Com as políticas de diminuição das taxas de emissão de $\mathrm{CO}_{2}$ na atmosfera surge a necessidade do desenvolvimento de novas formas de produção de hidrogênio, de forma limpa e ambientalmente segura. Nesse sentido, a clivagem fotocatalítica da água em $\mathrm{H}_{2}$ e $\mathrm{O}_{2}$ tem sido bastante estudada nos últimos anos. ${ }^{54-59}$ Esse processo baseia-se na absorção de luz por um semicondutor com concomitante geração de lacunas na banda de valência e elétrons na banda de condução. As lacunas geradas na banda de valência podem oxidar a molécula de água para formar $\mathrm{O}_{2}$, enquanto os elétrons da banda de condução podem ser transferidos para os prótons da água para produzir $\mathrm{H}_{2}$. Entretanto, a rápida recombinação elétron/buraco no semicondutor limita a eficiência dos materiais normalmente usados nesses processos fotocatalíticos. Além disso, considerando que apenas $4 \%$ da luz solar são devidos à radiação UV e cerca de 50\% devidos à luz visível, torna-se evidente a necessidade de se desenvolver novos materiais que possam absorver a maior parte da radiação que chega à superfície da Terra, i.e., radiação visível. Dentro deste contexto, a hematita tem sido amplamente estudada. Ela apresenta características interessantes para uso como fotocatalisador em sistema de produção de $\mathrm{H}_{2}$ via clivagem da água, como energia de band gap pequena o suficiente para absorver luz visível e grande o suficiente para quebrar a molécula de água, alta estabilidade nas soluções usadas para produção de $\mathrm{H}_{2}$, baixa toxicidade, custo de síntese barato e, ampla disponibilidade de precursores, uma vez que o Fe é o elemento mais abundante da Terra. Trabalhos recentes envolvendo a utilização de hematita dopada com diferentes cátions, como $\mathrm{Zr}, \mathrm{Sn}, \mathrm{Cu}, \mathrm{Ti}, \mathrm{Si}$, e Al, têm sido relatados na literatura. ${ }^{55-58} \mathrm{~A}$ substituição isomórfica do ferro por outros cátions altera a energia de band gap da hematita, diminuindo a probabilidade de recombinação elétron/buraco e, consequentemente, aumentando sua atividade fotocatalítica para produção de $\mathrm{H}_{2}$.

Recentemente, nosso grupo de pesquisa desenvolveu um novo material baseado em um oxidróxido de ferro, denominado $\delta$ - $\mathrm{FeOOH}$, que mostrou ser bastante promissor para uso em sistemas fotocatalíticos de produção de hidrogênio a partir da clivagem fotocatalítica da água usando luz solar. O material desenvolvido tem alta área superficial $\left(400 \mathrm{~m}^{2} \mathrm{~g}^{-1}\right)$, mesoporosidade entre as partículas, pequeno tamanho de partícula ( $10 \mathrm{~nm}$ ) e possui energia de band gap na região do visível. Isso permite que grande parte da luz solar seja usada para quebrar a molécula de água em $\mathrm{H}_{2}$ e $\mathrm{O}_{2} .{ }^{59}$

\section{Principais tipos de óxido de ferro}

A seguir, abordaremos de maneira sucinta uma descrição sobre os principais óxidos de ferro comumente empregados em processos catalíticos.

\section{Goethita}

A goethita é um mineral antiferromagnético do grupo dos oxidróxidos de ferro. Possui uma estrutura ortorrômbica (Figura 2) com cada íon $\mathrm{Fe}^{3+}$ coordenado com três íons $\mathrm{O}^{2-}$ e três íons $\mathrm{OH}^{-}$, formando octaedros. É um dos óxidos de ferro mais estáveis à temperatura ambiente. Entretanto, quando aquecida em temperaturas superiores a $200{ }^{\circ} \mathrm{C}$, sofre desidroxilação para formar hematita, $\alpha-\mathrm{Fe}_{2} \mathrm{O}_{3}{ }^{60}$

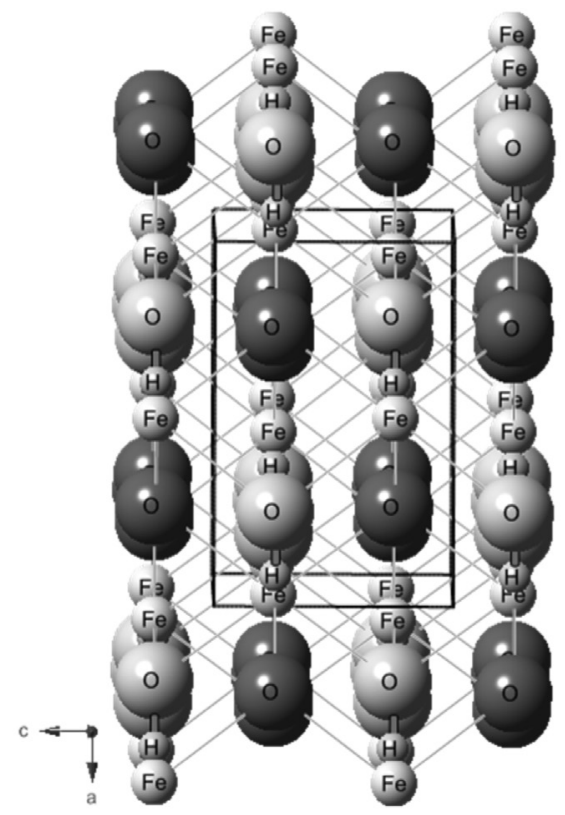

Figura 2. Estrutura cristalina da goethita

A goethita é o tipo de mineral de ferro mais difundido em sistemas naturais. ${ }^{61}$ Este óxido é normalmente encontrado na natureza como partículas de tamanho pequeno, ${ }^{62}$ influenciando o transporte e o destino dos numerosos íons e espécies aquosas. Assim, seu comportamento superficial tem sido amplamente investigado para um considerável número de adsorbatos iônicos ambientalmente relevantes.

A goethita natural contém impurezas de diferentes tipos de cátions metálicos, como $\mathrm{Al}^{3+}, \mathrm{Mn}^{3+}, \mathrm{Cr}^{3+}, \mathrm{Ni}^{2+}, \mathrm{Zn}^{2+}$ e $\mathrm{Pb}^{2+}$, incorporados em sua estrutura. ${ }^{61}$ Estas impurezas têm um impacto significativo sobre as propriedades da superfície da goethita e, por isso, muitos pesquisadores têm estudado a associação de goethita com outros elementos análogos sintéticos. ${ }^{63,64}$ Trabalhos científicos têm relatado que a capacidade de adsorção de goethita aumenta com a incorporação de íons metálicos em sua estrutura. ${ }^{65-68}$ No entanto, na maioria dos estudos relatados na literatura é dada atenção apenas à adsorção de arsenito e arsenato e muito pouco se sabe sobre a interação de goethita com outros oxiânions importantes, como fosfato, sulfato e cromato.

Wu et al. relataram a adsorção e transformação catalítica de $\mathrm{Cr}^{6+}$ em goethita dopada com Mn e mostraram que a adsorção de cromato em goethita pode ser melhorada com a dopagem com manganês, devido ao aumento da área específica. ${ }^{67}$

Mustafa et al. demonstraram que íons de níquel podem ser incorporados com sucesso na matriz de goethita, sem alterar a estrutura do cristal de base e que a dopagem com níquel aumentou a eficiência 
de adsorção de íons da goethita, devido ao aumento de sua superfície e volume de poros. ${ }^{69}$

Oliveira et al. relataram a utilização de goethita como catalisador em reações do tipo Fenton. A goethita possui uma estrutura menos compacta que outros óxidos de ferro, como a magnetita ou hematita que são óxidos comumente empregados nessas reações. ${ }^{26}$ Isso faz com que a substituição isomórfica na estrutura da goethita seja mais favorável, o que contribui para um considerável aumento na atividade catalítica em sistemas do tipo Fenton heterogêneo. ${ }^{70}$

\section{Magnetita}

A magnetita $\left(\mathrm{Fe}_{3} \mathrm{O}_{4}\right)$ é um mineral ferrimagnético que contém ferro em dois estados de oxidação, $\mathrm{Fe}^{2+}$ e $\mathrm{Fe}^{3+} \cdot{ }^{71,72}$ É uma fonte importante de minério de ferro, que é um óxido de ferro misto com $\mathrm{FeO}$ e $\mathrm{Fe}_{2} \mathrm{O}_{3}$, apresentando estrutura semelhante à montmorilonita, de espinélio invertida, com os íons $\mathrm{O}^{2-}$ coordenados tanto a íons $\mathrm{Fe}^{2+}$ e $\mathrm{Fe}^{3+}$, nos interstícios octaédricos, quanto a íons $\mathrm{Fe}^{3+}$ em interstícios tetraédricos (Figura 3). ${ }^{3}$ Como os íons $\mathrm{Fe}^{3+}$ são divididos igualmente entre as posições tetraédricas e octaédricas, não existe momento magnético resultante de presença destes íons. Entretanto, todos os íons $\mathrm{Fe}^{2+}$ residem nos interstícios octaédricos, sendo estes íons responsáveis pela magnetização de saturação ou, ainda, pelo comportamento magnético do material.

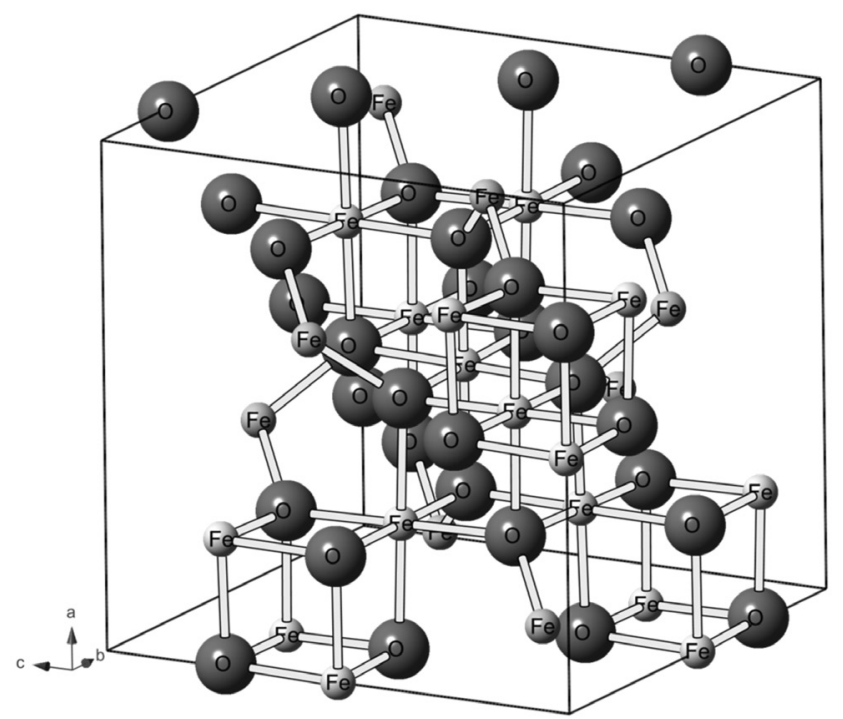

Figura 3. Estrutura cristalina da magnetita

Segundo Costa et al.,${ }^{35}$ a magnetita apresenta importantes características para uso em reações do tipo Fenton, pois o espinélio contém íons $\mathrm{Fe}^{2+}$, que tem importante papel como doador de elétrons para iniciar a reação Fenton. Além disso, os sítios octaédricos na estrutura da magnetita podem acomodar os íons $\mathrm{Fe}^{2+}$ e $\mathrm{Fe}^{3+} \mathrm{e}$, por isso, o $\mathrm{Fe}^{2+}$ pode ser facilmente oxidado de forma reversiva.

\section{Maghemita}

A estrutura da maghemita $\left(\gamma-\mathrm{Fe}_{2} \mathrm{O}_{3}\right)$ (Figura 4) é muito similar à da magnetita (estrutura cúbica de espinélio), porém a principal diferença é a presença de $\mathrm{Fe}^{3+}$ como o único cátion na estrutura. Cada célula unitária (cúbica) contém uma média de 32 íons $\mathrm{O}^{2-}, 21,33$ íons $\mathrm{Fe}^{3+}$ e 2,66 vacâncias, sendo que os cátions estão distribuídos em 8 sítios tetraédricos e 16 octaédricos. As vacâncias estão localizadas apenas nos sítios octaédricos. ${ }^{73}$

A maghemita é um óxido ferrimagnético à temperatura ambiente e suas propriedades magnéticas dependem do tamanho de partículas e dos efeitos de superfície. Partículas maiores que $10 \mathrm{~nm}$ são

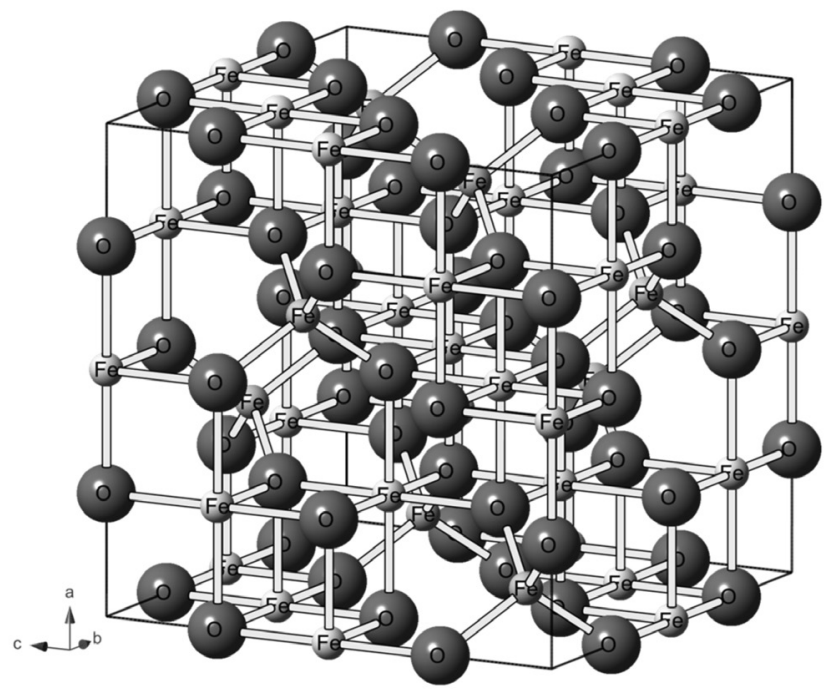

Figura 4. Estrutura cristalina da maghemita

magnéticas à temperatura ambiente, enquanto partículas menores são superparamagnéticas. ${ }^{74}$

Processos Fenton e foto-Fenton aplicados na presença de óxidos e oxidróxidos de ferro têm sido abundantemente relatados na literatura recente, principalmente em estudos de degradação envolvendo espécies de relevância ambiental (ex. corantes têxteis). Xugang $e t$ al. fizeram um estudo de fotodegradação do 2-mercaptobenzotiazol utilizando o óxido de ferro maghemita com oxalato, para simular ambientes aquáticos com a presença desses compostos, pois são encontrados em solos e águas de superfícies em regiões tropicais e subtropicais. ${ }^{75}$ Vários outros estudos realizados por Yanhui et al. mostraram o potencial fotocatalítico da maghemita, para a degradação de compostos orgânicos. ${ }^{76}$

\section{Hematita}

A hematita é o óxido de ferro conhecido há mais tempo pelo homem e está presente em rochas e no solo. Sua cor é vermelho sangue, de onde se origina o nome (do grego haima $=$ sangue). $\mathrm{O}$ óxido, de fórmula $\mathrm{Fe}_{2} \mathrm{O}_{3}$, consiste de lâminas de octaedros compartilhando arestas, com dois terços dos sítios ocupados por $\mathrm{Fe}^{3+} \mathrm{e}$ o restante arranjado regularmente, formando anéis hexagonais de octaedros (Figura 5). ${ }^{2}$ Como a goethita, ela é extremamente estável e muitas vezes é a última etapa na transformação de outros óxidos de ferro.

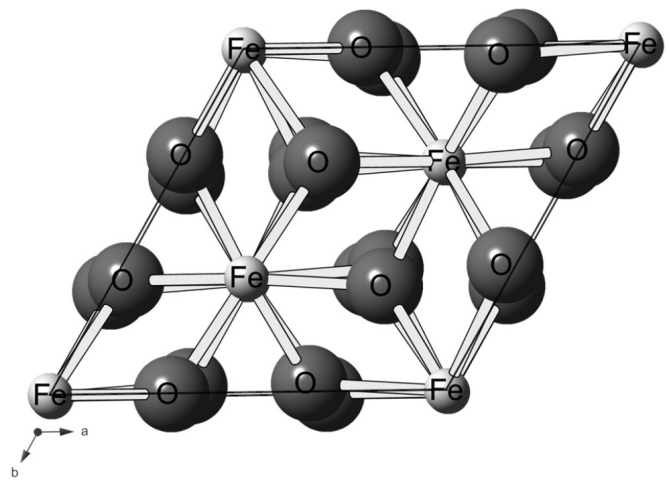

Figura 5. Estrutura cristalina da hematita

Devido às suas propriedades semicondutoras, a hematita tem sido estudada extensivamente em duas reações fotocatalíticas especiais 
- degradação de contaminantes em meio aquoso ${ }^{32}$ e produção de $\mathrm{H}_{2}$ via clivagem fotocatalítica da água. ${ }^{57}$ No primeiro caso, os buracos fotogerados na banda de valência são capazes de oxidar a molécula de água para formar espécies altamente oxidantes e não seletivas, i.e., radicais ${ }^{\bullet} \mathrm{OH}$, que são capazes de degradar importantes contaminantes orgânicos, tais como, compostos organoclorados e corantes têxteis, que são compostos de difícil destruição por métodos convencionais. Dependendo do grau de oxidação, as moléculas orgânicas podem ser completamente degradadas para formar $\mathrm{CO}_{2}$, água e sais minerais. No segundo caso, os elétrons fotogerados na banda de condução da hematita podem ser transferidos para os prótons da molécula de água para formar moléculas de $\mathrm{H}_{2}$.

\section{CONSIDERAÇÕES SOBRE A SÍNTESE DE ÓXIDOS DE FERRO}

Tendo em vista o uso dos óxidos de ferro como catalisadores, o processo de síntese deve levar em conta a obtenção de um produto com propriedades cuidadosamente controladas. Propriedades como tamanho de partícula e morfologia devem influenciar de maneira drástica a atividade catalítica dos materiais. Além disso, o custo de obtenção dos catalisadores dever ser um fator importante a ser considerado. Em geral, os materiais de partida na síntese de catalisadores de ferro envolvem principalmente sais de $\mathrm{Fe}^{2+}$ que são mais baratos que os sais de $\mathrm{Fe}^{3+}$. Existem três principais métodos de obtenção de catalisadores à base de óxidos de ferro: ${ }^{3}$

- reação em estado sólido pela decomposição térmica de sais de ferro ou ainda oxi-hidróxidos. Esse método pode promover a formação de hematita, goethita ou magnetita;

- processos de redução na presença de compostos orgânicos, o que levaria à formação de fases reduzidas como magnetita ou, mesmo, mistura de magnetita com maghemita;

- precipitação de sais de $\mathrm{Fe}^{2+}$ seguida de oxidação ou, mesmo, a precipitação de íons $\mathrm{Fe}^{3+}$ diretamente por hidróxidos de sódio ou potássio.

A morfologia dos catalisadores pode sofrer variações de acordo com o tipo de síntese, bem como as modificações empregadas, tais como, dopagem com metais ou impregnação com fases ativas. A Figura 6 apresenta duas imagens obtidas via microscopia eletrônica de transmissão para a hematita pura e o material dopado com nióbio. As imagens obtidas mostram que ao ser dopada com nióbio, a hematita apresenta uma forte diminuição do tamanho de partícula e aumenta sua área específica com possível melhoria nas suas propriedades catalíticas.

\section{CONCLUSÕES}

Um dos temas mais debatidos hoje é, sem dúvida, a busca de novos catalisadores ou rotas alternativas para a degradação de poluentes orgânicos, ou na catálise industrial. Os estudos envolvendo os óxidos de ferro demonstram que eles são promissores, devido à formação de espécies altamente reativas através do processo tipo Fenton, que é exclusivamente baseado no ferro. A possibilidade de se utilizar estes catalisadores vem representando uma significativa diminuição dos custos operacionais, considerando que os óxidos de ferro possuem uma eficiência superior aos catalisadores comerciais em condições de temperatura e pressão abaixo das relatadas e, também, apresenta uma resistência mecânica alta. Desta forma, o uso de óxidos de ferro como catalisadores em reações de degradação de compostos de origem petrolífera, fenóis, clorofenóis e na catálise de compostos de importância industrial, como a síntese de amônia e desidrogenação do etilbenzeno, é extremamente vantajosa, uma vez que facilita todas as etapas de operação do processo e diminui a geração de resíduos, (a)

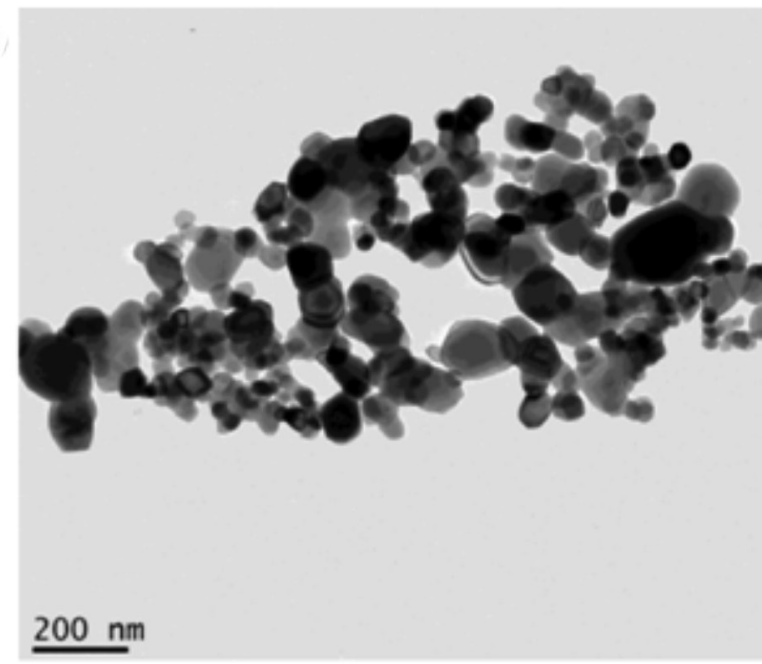

(b)

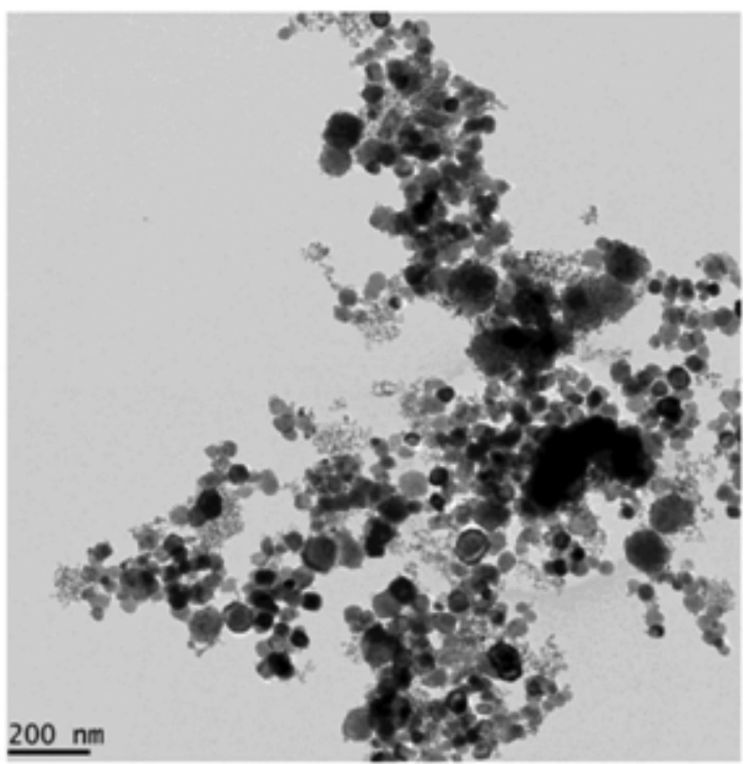

Figura 6. Imagens obtidas por microscopia eletrônica de transmissão evidenciando a diminuição no tamanho de partícula da hematita (a) pela dopagem com nióbio $(b)$

contribuindo para o desenvolvimento de processos baseados em Química Verde.

Os processos catalíticos heterogêneos promovidos por óxidos de ferro são fortemente afetados pelo tamanho de partícula, área específica, morfologia e substituição isomórfica do ferro por outros cátions. Nos processos fotocatalíticos a principal questão a ser resolvida ainda é a rápida recombinação dos pares elétrons/buraco no semicondutor. Para solucionar esses entraves tecnológicos, a substituição isomórfica do ferro por outros cátions tem sido amplamente estudada. Entretanto, a substituição isomórfica de íons oxigênio por ânions, como N, F, C, S, etc. tem sido pouco explorada até o momento e parece ser um caminho promissor para minimizar a rápida recombinação de cargas formadas durante o processo fotocatalítico. Outra alternativa interessante seria produzir compósitos semicondutores. Quando um semicondutor de band gap grande é acoplado com um semicondutor de band gap pequeno com o nível da banda de condução mais negativo, os elétrons da banda de condução podem ser injetados do semicondutor de band gap pequeno para o semicondutor de band gap grande, aumentando assim a separação de cargas. 


\section{AGRADECIMENTOS}

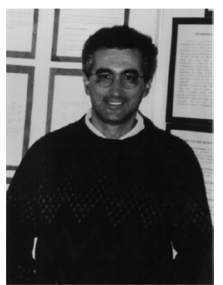

Prof. Milton F. Jesus Filho

(1947 - 1996)

Esse artigo é um tributo à memória do Prof. Milton Francisco de Jesus Filho, cuja dedicação à Química e desprendimento pessoal inspiraram e ainda são referências primordiais a seus colegas e alunos. O seu caráter amigável, sempre acompanhado de palavras de incentivo e encorajamento é lembrado sobretudo por aqueles que tiveram o grande privilégio de trabalhar com ele.

Financiamento: FAPEMIG, CNPq, CAPES.

\section{REFERÊNCIAS}

1. Coey, J. M. D.; Atom. Energy Rev. 1980, 18, 73

2. Guimaraes, I. R.; Oliveira, L. C. A.; Queiroz, P. F.; Ramalho, T. C.; Pereira, M.; Fabris, J. D.; Ardisson, J. D.; Appl. Catal., A 2008, 347, 89.

3. Schwertmann, U.; Cornell, R. M.; Iron Oxides in the Laboratory, $2^{\text {nd }}$ ed., VCH: Weinhein, 2000.

4. Goncalves, M.; Oliveira, L. C. A.; Guerreiro, M. C.; Quim. Nova 2008, 31, 518.

5. Pergher, S. B. C.; Oliveira, L. C. A.; Smaniotto, A.; Petkowicz, D. I.; Quim. Nova 2005, 28, 751.

6. Oliveira, D. Q. L.; Goncalves, M.; Oliveira, L. C. A.; Guilherme, L. R. G.; J. Hazard. Mater. 2007, 151, 280.

7. Rodrigues, J. A. R.; Quim. Nova 2011, 34, 1242.

8. Ximing, H.; Zhongtao, H.; Guobang, G.; Lefu, W.; Biyun, C.; J. Mol. Catal. A: Chem. 1998, 132, 171.

9. Centi, G.; Perathoner, S.; Pino, F.; Arrigo, R.; Giordano, G.; Katovic, A.; Pedulà, V.; Catal. Today 2005, 110, 211.

10. Ramirez, J. H.; Maldonado-Hódar, F. J.; Perez-Cadenas, A. F.; MorenoCastilla, C.; Costa, C. A.; Madeira, L. M.; Appl. Catal., B 2007, 75, 312.

11. Liu, H.; Li, X. Z.; Leng, Y. J.; Wang, C.; Water Res. 2007, 41, 1161.

12. Ntampegliotis, K.; Riga, A.; Karayannis, V.; Bontozoglou, V.; Papapolymerou, G.; J. Hazard. Mater. 2006, 136, 75.

13. Lu, M.; Chen, J.; Huang, H.; Chemosphere 2002, 46, 131.

14. Arends, I. W. C. E.; Sheldon, R.; Appl. Catal., A 2001, 212, 175.

15. Chou, S.; Huang, C.; Chemosphere 1999, 38, 2719.

16. Sutton, M. A.; Erisman, J. W.; Dentener, F.; Möller, D.; Environ. Pollut. 2008, 156, 583.

17. Eidus, Y. T.; Nefedov, B. K.; Petroleum Chemistry U.S.S.R. 1962, 1, 653

18. Silva, R. S. F.; Tamanqueira, J. B.; Dias, J. C. M.; Passarelli, F. M.; Bidart, A. M. F.; Aquino Neto, F. R.; Azevedo, D. A.; J. Braz. Chem. Soc. 2011, 22, 2121.

19. Tien-Thao, N.; Zahedi-Niaki, M. H.; Alamdari, H.; Kaliaguine, S.; Appl. Catal., A 2007, 326, 152.

20. Sie, S. T.; Krishna, R.; Appl. Catal., A 1999, 186, 55.

21. Andrade, A. L.; Souza, D. M.; Pereira, M. C.; Fabris, J. D.; Domingues, R. Z.; J. Nanosci. Nanotechnol. 2009, 9, 3695.

22. Pereira, M. C.; Tavares, C. M.; Fabris, J. D.; Lago, R. M.; Murad, E.; Criscuolo, P. S. R.; Clay Miner. 2007, 42, 299.

23. Pereira, M. C.; Coelho, F. S.; Nascentes, C. C.; Fabris, J. D.; Araújo, M. H.; Sapag, K.; Oliveira, L. C. A.; Lago, R. M.; Chemosphere 2010, 81, 7.

24. Oliveira, L. C. A.; Ramalho, T. C.; Souza, E. F.; Gonçalves, M.; Oliveira, D. Q. L.; Pereira, M. C.; Fabris, J. D.; Appl. Catal., B 2008, 83, 169.

25. Magalhães, F.; Pereira, M. C.; Bottrel, S. E.; Fabris, J. D.; Macedo, W. A.; Mendonça, R.; Lago, R. M.; Oliveira, L. C. A.; Appl. Catal., A 2007, $332,115$.

26. Oliveira, L. C. A.; Gonçalves, M.; Oliveira, D. Q. L.; Guarieiro, A. L. N.; Pereira, M. C.; Quim. Nova 2007, 30, 925.
27. Castro, C. S.; Guerreiro, M. C.; Oliveira, L. C. A.; Gonçalves, M.; Anastacio, A. S.; Nazzarro, M.; Appl. Catal., A 2009, 367, 53.

28. Nogueira, F. G.; Silva, A. C.; Lopes, J. H.; Lago, R. M.; Fabris, J. D.; Oliveira, L. C. A.; Appl. Clay Sci. 2011, 51, 385.

29. Kwan, W. P.; Voelker, B. M.; Environ. Sci. Technol. 2003, 37, 1150.

30. Tyre, B. W.; Watts, R. J.; Miller, G. C.; J. Environ. Qual. 1991, 20, 832.

31. Ramirez, J. H.; Lampinen, M.; Vicente, M. A.; Costa, C. A.; Madeira, L. M.; Ind. Eng. Chem. Res. 2008, 47, 284.

32. Silva, A. C.; Cepera, R. M.; Pereira, M. C.; Lima, D. Q.; Fabris, J. D.; Oliveira, L. C. A.; Appl. Catal., B 2011, 107, 237.

33. Silva, A. C.; Oliveira, D. Q. L.; Oliveira, L. C. A.; Anastácio, A. S.; Ramalho, T. C.; Lopes, J. H.; Carvalho, H. W.P.; Torres, C. E. R.; Appl. Catal., A 2009, 357, 79.

34. Guimaraes, I. R.; Giroto, A.; Oliveira, L. C. A.; Guerreiro, M. C.; Lima, D. Q.; Fabris, J. D.; Appl. Catal., B 2009, 91, 581.

35. Costa, R. C. C.; Lelis, M. F. F.; Oliveira, L. C. A.; Fabris, J. D.; Ardisson, J. D.; Rios, R. V. A.; Lago, R. M.; J. Hazard. Mater. 2006, 129, 171.

36. Costa, R. C. C.; Lelis, M. F. F.; Oliveira, L. C. A.; Fabris, J. D.; Ardisson, J. D.; Rios, R. V. A.; Lago, R. M.; J. Catal. Commun. 2003, 4,525 .

37. Castro, C. S.; Guerreiro, M. C.; Goncalves, M.; Oliveira, L. C. A.; Anastacio, A. S.; J. Hazard. Mater. 2009, 164, 609.

38. Prihodko, R.; Stolyarova, I.; Gündüz, G.; Taran, O.; Yashnik, S.; Parmon, V.; Goncharuk, V.; Appl. Catal., B 2011, 104, 201.

39. Xia, M.; Long, M.; Yang, Y.; Chen, C.; Cai, W.; Zhou, B.; Appl. Catal., $B$ 2011, 110, 118.

40. Herney-Ramirez, J.; Silva, A. M. T.; Vicente, M. A.; Costa, C. A.; Madeira, L. M.; Appl. Catal., B 2011, 101, 197.

41. Fontecha-Cámara, M. A.; Álvarez-Merino, M. A.; Carrasco-Marín, F.; López-Ramón, M. V.; Moreno-Castilla, C.; Appl. Catal., B 2011, 101, 425 .

42. Oliveira, L. C. A.; Goncalves, M.; Guerreiro, M. C.; Ramalho, T. C.; Fabris, J. D.; Pereira, M. C.; Sapag K.; Appl. Catal., A 2007, 316, 117.

43. Nogueira, R. F. P.; Jardim, W. F.; Quim. Nova 1998, 21, 69.

44. Bahnemann, D.; Sol. Energy 2004, 77, 445.

45. Alberici, R. M.; Jardim, W. F.; Appl. Catal., B 1997, 14, 55.

46. Li, F. B.; Wang, X. G.; Li, Y. T.; Liu, C. S.; Zeng, F.; Zhang, L. J.; Hao, M. D.; Ruan, H. D.; J. Colloid Interface Sci. 2008, 321, 332.

47. Malato, S.; Blanco, J.; Alaerco, D. C.; Maldonado, M. I.; Ibanez, P. F.; Gernjak, W.; Catal. Today 2007, 122, 137.

48. Menini, L.; Pereira, M. C.; Parreira, L. A.; Fabris, J. D.; Gusevskaya, E. V.; J. Catal. 2008, 254, 355.

49. Menini, L.; Pereira, M. C.; Ferreira, A. C.; Fabris, J. D.; Gusevskaya, E. V.; Appl. Catal., A 2011, 392, 151.

50. Basu, B.; Satapathy, S.; Bhatnagar, A. K.; Catal. Rev. 1993, 35, 571.

51. Shirini, F.; Zolfigol, M. A.; Khaleghi, M.; Mendeleev Commun. 2004, 14,34 .

52. Shaabani, A.; Lee, D. J.; Tetrahedron Lett. 2001, 42, 5833.

53. Nakagawa, K.; Shiba, S.; Horikawa, M.; Sato, K.; Nakamura, H.; Harada, N.; Harada, F.; Synth. Commun. 1980, 10, 305.

54. Ni, M.; Leung, M. K. H.; Leung, D. Y. C.; Sumathy, K.; Renew. Sust. Energ. Rev. 2007, 11, 401.

55. Kumar, P.; Sharma, P.; Shrivastav, R.; Dass, S.; Satsangi, V. R.; Int. J. Hydrogen Energ. 2011, 36, 2777.

56. Ling, Y.; Wang, G.; Wheeler, D. A.; Zhang, J. Z.; Li, Y.; Nano Lett. 2011, $11,2119$.

57. Meng, X. Y.; Qin, G. W.; Li, S.; Wen, X. H.; Ren, Y. P.; Pei, W. L.; Zuo, L.; Appl. Phys. Lett. 2011, 98, 112104.

58. He, J.; Parkinson, B. A.; Comb. Sci. 2011, 13, 399.

59. Pereira, M. C.; Garcia, E. M.; Silva, A. C.; Lorençon, E.; Ardisson, J. D.; Murad, E.; Fabris, J. D.; Matêncio, T.; Ramalho, T. C.; Rocha, M. V. J.; J. Mater. Chem. 2011, 21, 10280. 
60. Pereira, M. C.; Cavalcante, L. C. D.; Magalhães, F.; Fabris, J. D.; Stucki, J. W.; Oliveira, L. C. A.; Murad, E.; Chem. Eng. J. 2011, 166, 962.

61. Gao, Y.; Mucci, A.; Geochim. Cosmochim. Acta 2001, 65, 2361.

62. Waychunas, G. A.; Kim, C. S.; Banfiekd, J. F.; J. Nanopart. Res. 2005, 7, 409.

63. Manceau, A.; Schlegel, M. L.; Musso, M.; Sole, V. A.; Gauthier, C.; Petit, P. E.; Trolard, F.; Geochim. Cosmochim. Acta 2000, 64, 3643.

64. Davis, A. P.; Upadhyaya, M.; Water Res. 1996, 30, 1894.

65. Chakravarty, S.; Dureja, V.; Bhattachayya, G.; Maity, S.; Bhattachajee, S.; Water Res. 2002, 36, 625.

66. Alvarez, M.; Rueda, E. H.; Sileo, E. E.; Geochim. Cosmochim. Acta 2007, 71, 1009

67. Wu, W. C.; Wang, S. L.; Tzou, Y. M.; Chen, J. H.; Wang, M. K.; Appl. Catal., B 2007, 75, 272.

68. Mohapatra, M.; Sahoo, S. K.; Anand, S.; Das, R. P.; J. Colloid Interface Sci. 2006, 298, 6.
69. Mustafa, S.; Khan, S.; Zaman, M. I.; Water Res. 2010, 44, 918.

70. Santos, C. A.; Horbe, A. M. C.; Barcellos, C. M. O.; Cunha, J. B. M.; Solid State Commun. 2001, 118, 449.

71. Santana, G. P.; Ramos, A. M.; Fabris, J. D.; Quim. Nova 2008, 31, 430.

72. Silva, M. J.; Bernadou, J. P.; Garcia, A.; Anais do $49^{\circ}$ Congresso internacional de tecnologia metalúrgica e de materiais, Anhambi, Brasil, 1994.

73. Karunakaran, C.; Senthilvelan, S.; Electrochem. Commun. 2006, 8, 95.

74. Araujo, G. A.; Souza, A. O.; Rangel, M. C.; Quim. Nova 2002, 25, 181.

75. Meifang, H.; Hongfu, W.; Tinglin, L.; Yanning, F.; Xinming, L.; Xugang, W.; Appl. Catal., B 2008, 84, 170.

76. Yanhui, A.; Jingjing, X.; Degang, F.; Chunwei, Y.; J. Alloys Compd. 2009, 471, 33. 